\title{
In, out and through digital worlds. Hybrid-transitions as a space for children's agency
}

\author{
Angela Scollan ${ }^{\mathrm{a}}$ and Federico Farini ${ }^{\mathrm{b}}$ \\ ${ }^{a}$ Department of Education, Middlesex University \\ ${ }^{b}$ Department of Applied Social Sciences and Sociology, University of Northampton
}

\begin{abstract}
A rich tradition of pedagogical and psychological research has explored the impact of technology on the cognitive and social development of the child. However, little research has focused on the implications of the use of digital technologies in educational settings for children's agency. This article introduces hybrid-transitions as a theoretical tool to conceptualise transitions between the use of digitally enhanced and non-digitally enhanced experiences as dense social spaces where young children show agency in the construction and coconstruction of knowledges. Hybrid-transitions refers to children's movement from the immersion in digitally-enhanced experiences generated by educational technologies to non-digitally mediated interactions with peers or adults. This article argues, with the support of examples, that during hybrid transitions digital experiences are shared via personal narratives linking ideas, experiences and emotions. Individual narratives are "interlaced" in co-constructed group narratives authored by the children through face to face interactions. The interactive authorship of interlaced narratives is discussed as a form of agency, as it includes making choices regarding action and understanding of action. This article intends to promote attention to hybrid-transitional spaces among adults who work in educational settings where digital technologies are utilised.
\end{abstract}

Keywords: hybrid-transitions; narratives; agency; digitally-enhanced learning; adult-child interaction

\section{Introduction: hybrid-transitions as spaces of children's agency}

Although Prensky's dichotomy 'digital natives/digital immigrants' (2001) has been object of criticism (Helsper and Eynon 2010; Stephen and Plowman 2014), an apparent correlation between age and resistance towards digital technology has been triggering 
research in social sciences, pedagogy, computer sciences, psychology and marketing (Buckingham, 2002; Edwards, 2013; Marsh, 2010). In particular, pedagogical and psychological research has explored the impact of technology on the cognitive and social development of the child (Siraj-Blatchford, 2006, Morgan and Siraj-Blatchford 2013, Levin, 2013, Marsh, 2010). However, there is still limited research on the implications of the educational use of digital technologies for children's agency.

Based on ethnographic observations, this article discusses interactions when children combine digitally-enhanced and non-digitally-enhanced experiences to coconstruct narratives, showing agency by claiming authorship of valid knowledge. Hybrid-transitions is introduced as a theoretical tool to investigate young children's transitions between digitally-enhanced and non-digitally enhanced experiences as a space where children generate and access domains of knowledge. 'Hybrid' refers to children's movement between digitally-enhanced and non-digitally enhanced experiences, that can be combined to construct new knowledge. Rather than temporal sequences, hybrid-transitions are understood as social spaces where children combine digitally-based and non digitally-based experiences in the construction or coconstruction of narratives, taking the role of autonomous authors of knowledge. It is argued that by claiming authorship of knowledge, children display agency. In particular, as authors of narratives, children display a type of agency that concerns their epistemic status. A discussion to clarify the semantics of agency underpinning this article is provided in the following section. 


\section{An epistemic approach to children's agency: children constructing and co- constructing knowledge}

Agency is a key concept in childhood studies (James, 2009; James and James, 2008; Leonard, 2016; Oswell, 2013). Agency does not only refer to participation in social situations, but also to the ability to act autonomously from external conditions. James and James (2008: 9) define agency as 'the capacity of individuals to act independently'. However, there are other conceptions of agency. The concept of agency can trespass the boundaries of capability to indicate children's participation that enhances social change, at least within specific social interactions (Bae, 2012; Bjerke, 2011). The conception of children's agency as social participation rather than individual attribute implies the relationship between children's actions and social structures (Oswell, 2013). Agency indicates a form of social participation where children's actions are not determined by adults' actions. Although important social constraints for children's autonomous actions are acknowledged (Bjerke, 2011; James, 2009; James and James, 2008; Moosa-Mitha, 2005; Valentine, 2011; Oswell, 2013; Wyness, 2014; Baraldi, 2015; Author, 2018), the relational conception of agency recognises that structures and individual actions are intertwined at the level of social practices (Giddens, 1984).

In this article, agency is observed through children's autonomous access to domains of knowledge, what Heritage (2012) calls epistemic status. Agency is also observed through children's rights and responsibilities for constructing knowledge, what Heritage and Raymond (2005) call epistemic authority. Children's epistemic authority indicates agency because it entails autonomous capacity of 'acting' knowledge in social interactions (Bath, 2013; Dahlberg and Moss, 2005; Moss, 2009; Pascal and Bertram, 2009). In this article, children's epistemic status and epistemic authority are recognised in their authorship of stories and knowledges within a seamless transition 
between the use of digitally-enhanced and non-digitally-enhanced experiences. In line with a strong tradition in research, constructing and sharing knowledge is considered as an instance of children's capability to both shaping their own lives and influencing their social contexts (Lansdown, 2005; Markstroem and Halladén, 2009; Baraldi, 2014). This article argues that by constructing narratives combining experiences based on the use of digital technologies and experiences non-mediated by digital technology, children display agency. The construction of narratives displays agency because it is underpinned by children's choices. The construction of narratives displays agency also because narratives influence the context of children's social participation, for instance opening the possibility for the development of mobile identities connected, including temporary but important 'small group cultures' (Hollyday, 2011).

\section{Hybrid-transitions in the use of digital technology to support communication skills: a case from Boston}

Influential research in Early Years education (Marsh and Bishop, 2014; Plowman et al., 2008; Levin-Gelman, 2014) recognises the need for adults to be aware of the learning opportunities accessible to children via digital engagement. The focus of those studies is on adults' position, with limited consideration to children's use of both digital and nondigital resources to autonomously access domains of knowledge. However, recent pedagogical researches have invited adults to reflect on the importance of supporting children in the transition between the digitally enhanced and non-digitally enhanced experiences (Author, 2016), translating into digital landscapes classic research on transitions between play and structured learning activities (Dunn, 1988; Dunn and Ploumin, 1990; Lam and Pollard, 2006; Johansson, 2007).

In the literature examined, the plea for systematic attention to transitions between digital and non-digital worlds is accompanied by the awareness that inter- 
generational conflict can coagulate around the use of digital technologies, following Prensky's suggestions (Marsh, 2010; Levin, 2013). Research presenting a more positive outlook regarding the possibility for the adult to manage digital learning opportunities (Edwards, 2013b; Plowman et al., 2009) is nevertheless based on Prensky's argument about the fatigue of immigrated adults attuning with digital technologies. Either pessimistic or optimistic about the intersection of digital technologies and generational relationships, research has been concerned about the use of digital technologies for children's learning rather than focusing on children's active role as authors of knowledge as they move between digitally enhanced experiences and non-digitally enhanced experiences. This article provides fresh research at the intersection of children's agency and adults' reaction to the expression of it. An ethnographic study is presented, and the discussion is centred around examples of children authoring the construction of knowledge as they combine digitally-enhanced and non-digitally enhanced experiences during educational activities in a pre-kindergarten. The discussion of field notes supports the claim that hybrid-transitions are spaces of children's agency. Field notes are combined with transcripts of interactions between children, audio-recorded by the researcher using a small portable device, upon consent granted by the pre-kindergarten management, children's guardians and children. The same researcher transcribed the data using software licensed for General Public use. Whilst the transcription aimed at the highest level of accuracy, the researcher did not utilise Conversation Analysis convention (Hepburn and Bolden, 2013) to mark pitch, pace and tone of delivery, as deemed unnecessary considering the nature of data and the scope of analysis. Descriptions of relevant non-verbal behaviour were added to the relevant transcripts based on field notes. They are presented between square brackets in the article. 
The study concerns digitally-based learning activities observed in a prekindergarten in Boston. Although research suggests that not enough has been invested for young children, children's services and early years provision in the United States (Mongeau, 2016; Mosley, 2016) the City of Boston is a leading force in the public sponsoring of pre-schools (The National Institute for Early Education Research, 2017). An example is provided by the pre-kindergarten where the observation took place, one of the 3,100 community-based pre-schools in Massachusetts benefitting of both local funds and funds from the 2015 Federal Preschool Expansion Grant initiative (Boston Early Education Department, 2016). The setting of the observations is located in a highly ethnically diverse residential Boston neighbourhood, with a percentage of nonU.S. citizens higher than $50 \%$. The setting is licensed for a 45 children capacity, that was fully used at the time of the observation. Children enrolled in the settings are between 2 and 5 years old, many from Hispanic/Latino background.

This article discusses data produced through participant observation. Participant observation allows for richly detailed description, whilst providing opportunities for viewing or participating in unscheduled events (Fine, 2003). Plowman's thoughts on the difficulties of distinguishing relevant information from noise in ethnographic research has been acknowledged in the design of the research, leading to reflecting on the pivotal role of a clear focus. The focus was identified in children's combination of digitally-enhanced and non-digitally-enhanced experiences to construct and coconstruct knowledge in interactions. The identification of a focus for observation was facilitated by the authors' previous experiences at the intersection of research and practice of working with children and digital technologies (Author, 2016).

The observations concerned the use of a software for the development of communication skills for children having English as second language. The age of 
children is between 3 and 4 years; 3 adults were present, 2 in addition to the researcher, who is also one of the authors of this paper. In the setting of the research, 2 personal computers were provided with the communication skills software installed, allowing four children to work at the same time, 2 for each computer, over 30 minutes sessions in the early afternoon. In total, 8 children were observed using the software over two weeks. The researcher observed children and their interactions during the use of digital learning technologies, as well as in its aftermath when children re-joined the group. The researcher did not take part in children's use of software and in the following interactions. Observations were facilitated by the culture of Early Years education, where observations are one of the most important aspects of day-to-day professional practice. The research was underpinned by a robust ethical framework, based on American guidelines for working with children (APA, 2004), integrated with British (BERA, 2014) and European (EECERA, 2015) guidelines. Data collection was undertaken ensuring there was no harm to participants and stored securely adhering to the EU GDPR (2018). The research sought and obtained approval from the authors' institutions ethics committees.

All observations undertaken with children were conducted working closely with the headteacher and classroom staff to seek advice and respond to concerns. Information on research methods were provided to participants in advance. Consent was secured prior to collection and processing of all data. Consent on behalf of children was sought from guardians and collected in collaboration with the pre-kindergarten staff in written form. Children were directly informed about the research activities and their assent was sought using an accessible pictorial language. Assent from children and consent from teachers and parents was understood as a living and fluid agreement. For the authors, research is an ongoing and unfolding process aiming to open spaces of 
dialogue for children to express and share their interests. How and why children voice these interests is a key research focus and therefore children's active participation is needed. However, it is important to point out that whilst active participation is key, it can only occur if children choose to give their assent as fully active and willing participants. Assent from children was obtained verbally prior to each activity and was monitored during the research by continuously scrutinising children's behaviour to spot any sign of distress and discomfort. Prior to research being undertaken the researcher joined the group for two days to develop a relationship with children and teachers. Developing a relationship with participants in preparation for the research allowed children plenty of opportunities to ask informally about the research or purpose of the researcher being in the classroom. As an established educationalist and practitioner, the researcher systematically checked before and after each recorded observation if children wish to withdraw. Opportunities for children to talk to the researcher outside of the activity and peer group was made available in case children feel pressured or unable to withdraw while in presence of the peer-group.

Any potential breach of confidentiality and data protection in relation to research data was minimised using password-protected storage. All personal information, and analysed data were stored in encrypted and locked files. Further data protection ensured that no data was exchanged between the authors via email or stored electronically on devices linked to the Internet. The authors made sure to respect EU Directive 95/46/EC, the updated New General Data protection regulation 2106/679 and other relevant EU legal instruments when working with personal data. This is a key aspect of the research approach being adopted. Raw data was only accessible to the researchers, and processed data does not include any reference to personal data to prevent identification. 


\section{Analysis and findings}

The setting of the research is characterised by continuing pedagogical investment in monitoring and supporting the development of communication skills, as many children come from recent immigration backgrounds, and have English as a second or third language. The development of communication skills is a core area for practice in the setting: children's self-expressive language skills are emphasised in everyday interactions, both with adult and peers. The learning activity observed by the researcher and presented in this section was concerned with the development of communication skills. The activity was therefore important in the setting's pedagogical planning.

In the kindergartner, children engage with a range of natural and organisational reading strategies within an environment enhanced by pedagogical innovation and teaching creativity that aims to support reading skills and engagement. However, when children are invited to undertake teacher-led reading activities, reading can become purposeful or assessed. Learning software can be similarly directive but it is here argued, based on observations undertaken, that when children engage with computer programmes a more informal experience may develop because responses and reactions can be owned and managed by the child within unplanned interactions.

In the observations undertaken, whilst the software used by the children aimed to develop phonics and literacy skills to support reading, children also interacted with the programme exploring contextualisation and meaning with physical manipulation of the keyboard, mouse and screen as well as through responding to peers.

In this section, the analysis of a learning activity is presented, based on the researcher's field notes and transcripts of audiotaped interactions. The activity involves two children, aged three and four years, playing a 'vampire' game where images are bouncing across the screen. Every time three words starting with the letter ' $\mathrm{V}$ ' are 
correctly pointed, a vampire gives a deep and scary long laugh. The field notes report that, during their digital gameplay

the two children squealed with delight...thoroughly enjoying being scared whilst observing each other's reaction and facial contortions. Enthusiastic screams were undertaken simultaneously with both children theatrically trying to be the most scared, scariest and alarmed. In fact, a competition to outdo each other could even be seen erupting to combine their unique reactions and experiences

(field notes from the researcher)

The digitally-enhanced experience becomes the pivot for children's agency, expressed in the use of the software as a resource for playing, role-playing and interaction. From the digital experience, a rich array of non-digital face-to-face interactions develops. This is suggested from the field notes below, documenting a change in the social situation when four children join the pair, attracted by their expression of excitement and delight.

The sheer joy they displayed during this activity enticed another four children to join them. Child 'A' continued to control the mouse, child 'B' continued to point to the screen to words beginning with the letter ' $V$ ', whilst children ' $C$ ', ' $D$ ', ' $E$ ' and 'F', who recently joined the activity, interacted, colluded, negotiated, problem solved and swapped vampire scary stories from a recent TV programme and birthday party they had experienced

(field notes from the researcher)

The co-construction of narratives represents a form of agency within the peer-group, because it implies children mutually recognising their statuses as producers of valid knowledge and meanings (Iervese and Baraldi, 2017). In the transcript presented below, three children co-operate combining narratives of personal experiences (Child P, 'my sister has fangs...'), knowledge on Vampire physiology (Child L, 'fangs are like straws and suck up blood like a strawberry milkshake') and technical skills in the use of the software (Child M, 'look what happens when I press this, I bet fangs come out'). 
Children's co-operation develops as seamless transitions between the digital-based experiences and non-digital based experiences.

Child L: 'you should have pressed that button, not that one!'

Child M: 'no'

Child L: 'yes because when you press it he waves his arms up and shows his fangs' [Child M shrugs and ignores advice]

Child P: "my sister has fangs and she dribbles when there in her mouth. She tries to bite me and chases me...I run away from her, it's fun but I was scared when I ran and then fell over'

Child L: 'yes fangs are scary they are like straws and suck up blood like a strawberry milkshake'

Child P: 'ehhhh errrrrrr it's not like a milkshake [laughs and then sticks teeth out to indicate fangs]

Child L: 'teeth are fangs, we have fangs like him (points to screen and vampire)

Child M: 'look what happens when I press this...I bet his fangs come out!'

Child L: 'yeah look' [opens mouth wide and sticks teeth out mimicking onscreen vampire waving arms up and down]

[Child P: mimics actions of the vampire and Child L]

(transcripts from the researcher)

The shared construction of narrative documented by the transcript above is underpinned by frictionless movement between digitally-based experiences and the nondigitally based experiences. The material substrate of experiences (digital play and nondigital interactions) are two components of the same changing, fluid, but nevertheless unified, life-world. The observations undertaken suggest that whilst emerging from different substrata, digitally-enhanced experiences and non-digitally enhanced experiences were both used by children to produce complex texts built through negotiation and creative combination of individual authorship. The transcript below reports an interaction between children. The context of the interaction is the use of the computer keyboard by Child B to play the Vampire game. Child B transitions from digital to non-digital experiential realms to share a personal memory ('I dressed up I 
had a cape and put hair gel...'). This narrative is presented as a 'real' vampire experience as opposed to the 'boring' predictability of the game. Child L connects a piece of knowledge about Vampires' behaviour to Child B's narrative. An interlaced, co-constructed, narrative emerges in the transitions between the use of non-digital resources and digitally-based resources. Children autonomously access the status of knowledgeable producers of information. It is argued that this elevates the interlaced narrative to an example of children's agency. Child A and Child Z contribute to the narrative by reinforcing its validity (Child A's question legitimises the narrative produced) and taking a role within it, thus crossing the boundaries between narration and representation (Child $\mathrm{Z}$ personifies a vampire). Authorship of knowledge across digitally-enhanced and non-digitally enhanced experiences is not the only way for children to display agency. Another important aspect is their ability to cooperate in the construction of knowledge. During the observations of digitally-enhanced learning, personal narratives, ideas, experiences and emotions were "interlaced" in co-constructed group narratives, co-authored by the children.

Child B: (to the researcher) 'this is boring [points at the screen] he is not scary at all I know everything he will do...he doesn't drink blood or anything...look!' [continues to look at the screen] 'I dressed up I had a cape and put hair gel into my hair so it looked wet...like a real vampire look'

[Child L leans forward and presses keyboard]

Child L: 'yes they are real and they do drink blood, they will drink your blood and you will die for a while and then be up again'

[Child B pushes Child L hand to prevent the keyboard being interfered with]

Child B: 'it's not your turn yet, I haven't finished to get all the letters'

Child L: 'you're a vampire now too' [laughs and leans forward to press another button]

Child A: 'you're not a scary vampire are you?

Child L: 'yeah you're a friendly vampire and we will all go to the party and dance, we won't be scared at all, will we?' 
[Child $\mathrm{Z}$ raises arms up and stares directly at both children and then begins to flap his arms up and down]

[Child A and Child L laugh and scream]

[Child $\mathrm{Z}$ responds by making gurgling sounds moving his face nearer to both] (transcript and notes from the researcher)

Observation of others, as much as self-observation, is impacted by agendas, expectations and identities that largely determine what is seen and what it is unseen (Dewey, 1966; Moon, 1999; Bolton, 2010). Professional cultures and habits can filter adults' insight into children and into the worlds they enter. The following excerpt from the field notes concerns a very important aspect correlated to hybrid transitions: the reaction of the practitioner to the child's use of knowledge and experiences matured through hybrid transitions. Digital scotoma is here introduced to describe the relationship between adults' and children's diverging semantics and approaches to the use of digital technology. Digital scotoma indicates a blind spot that prevents the adult to acknowledge the creativity, possibilities and learning generated in hybrid-transitions. As the scotoma of the eye, the blind spot in the digital scotoma is surrounded by a field of normal vision. This may explain the observed paradox between child-centred pedagogical planning and the frequent practitioners' inability to detect children's display of agency in creating stories and knowledge. The field notes below illustrates an example of digital scotoma. The researcher notes that child D

is immersed and excited during the above 'vampire' scenario and seems to be enjoying the interaction with peers and the vampire play. Child D creatively interacted both with the digital resource and with peers, co-authoring interlaced narratives in the transition between the use of digitally and non-digitally enhanced experience. For instance, he managed game rules whilst contributing towards construction of new ones, at the same time transforming his and other children's memories as a resource to generate new narratives in the present 
Wohlend claims that children can co-author interactive stories, negotiating tensions among their individual moves in a fluid action-packed scene (Wohlend, 2016). Her conclusion resonates in the researcher's field notes presented below. The field notes report the intervention of a practitioner, attracted by the vibrant atmosphere around the computer.

a practitioner joins the group to reiterate agreed rules that "only two children at a time should be using the computer". Four children (including child D) were encouraged to leave the computer area and join in with a structured adult led activity. The group disbanded and instantly the richness of the world they had entered shifted. Child D continued to laugh whilst using a substantial vampire voice, physically making vampire movements to continue his exploration. His play and agenda seemed to continue with or without the computer and his creative and cognitive skills applied during the observed 'vampire play' were transferred between the digital realm and into non digitally mediated interactions. The transition was fast and purposeful

(field notes from the researcher)

Child D transitions between the digital and non-digital realms effortlessly, again challenging the idea of ontological separateness of the two. Rather, child D makes the transition itself a space to display agency and to recognise other children's agency as he incorporates their stories in his playing. Reflecting upon the point above where the children are disbanded by an adult intervention, it is pertinent to wonder what happens to the space and context constructed and visited by the children. For instance, are the shared experiences during hybrid-transitions stored on a 'social hard drive' by their authors, to be managed and revisited? Are the experience and space similar to a snowflake melting on the ground, vanishing in the milieu? Whilst immersed in the continuing hybrid transitions, child D leaves when asked, to move to the area suggested 
by the practitioner. However, even when firmly positioned in the non-digital realm, he continues to author his own social participation, building on the combination between digital experiences and not digital experiences to develop narratives around the vampire theme. Child D transports his script into new realms and spaces during hybridtransitions. The field notes register the conclusion of the exchange when

the practitioner asked child D to stop using a loud voice and "stop being silly" whilst he created flying actions whilst swishing around and flapping on a curtain (field notes from the researcher)

The form of engagement used by the practitioner during the observed activity suggests that the recognition and acceptance of children's agency may encounter obstacles when the importance of hybrid transition is not recognised. A space where children author knowledge based on experiences and interaction is closed by the intervention of the practitioner. This might raise question about the impact of such intervention on children's learning and development that the provision of digital technology was aimed at. Hybrid-transitions produce various levels of children's participation that can be promoted as expressions of children's agency or refused as disruptive for educational planning. For instance, does child D receive space to express choice, knowledge or creativity? Does he receive space to experience or consolidate the knowledge he has coconstructed with peers? Or, taking a more pedagogical approach, does child D get recognition for communication skills demonstrated?

Three main themes emerge from the findings. The first theme is the different scene that children and adult seem to see when looking at the use of digital technologies. Whilst the adults calculate a balance between risk and opportunity for children's learning, seeing the digital as an instrument towards successful development, the children see social spaces where digital and non-digital resources are seamlessly 
combined to author knowledges and narratives. This claim introduces a second theme underpinning this article: the observations undertaken evidence that digitally enhanced experiences are used and exchanged in non-digitally mediated interactions, as well as non-digitally enhanced experiences enrich the use of digital resources.

A third theme from our findings is linked to a sociological interpretation of hybridtransitions as spaces of children's agency, where knowledge generated through digital resources is used to support autonomous choices in non digitally-mediated interactions, and vice-versa. This continuum is the social and temporal condition of hybridtransitions. How Early Years Education acknowledges, provides for and supports hybrid-transitions are all aspects that deserve reflection and discussion.

\section{Discussion}

An important aspect of children's creativity in combining digitally-enhanced and nondigitally enhanced experiences concerns sharing personal memories towards the coconstruction of interlaced narratives (Norrick, 2007; 2013; Stone and Bietti, 2016). Similarly to the co-construction of narratives discussed in the findings section, collaborative practices during digital gameplay have been discussed by Danby and colleagues (2018) who demonstrate how children collaborate with one another during digital gameplay, including intense communication to instruct each other, monitoring each other's actions and problem solving. Danby and colleagues suggest that multimodal interactions during digital gameplay create opportunities for peer and sibling learning without the presence of an adult, displaying agency in learning through social interaction and gameplay. It is believed that the same interpretation may be extended to the interactive co-construction of narratives observed in the settings by the researcher. 
From a perspective focused on the social use of digital technologies by young children, the idea of a separation between digital world and non-digital world appears to be non-tenable as a theoretical position. This observation builds on Danby and colleagues (2015) argument in favour of pre-schoolers' ability to implement their 'desire to know' by engaging with an online program such as Google Earth and populating the representations of spaces and places created by a mapping software with memories and narratives of their everyday, non-digitally mediated, encounters. In a similar fashion, notwithstanding different methodological approaches, Freeman and colleagues (2015) celebrate children showcasing knowledge of local spaces when presented online aerial photographs; the interesting aspect of the research was that children can insert their 'grounded' knowledge of places into representation that largely differ from the ordinary sensory experiences. Freeman and colleagues' results are particularly relevant if combined with the results of the research discussed in this article: both researches point to young children who demonstrate the ability to insert everyday experiences into texts composed using digital resources.

The group of children observed in our research seem to effortlessly connect and understand their shared movement through 'hybrid-transitions' between the use of digital resources and non-digital resources. This observation aligns with Wohlwend's research on digital literacy practices that emerge when young children play together with digital apps on touchscreen devices (Wohlwend, 2016). Wohlwend demonstrates that children's collaborative composing with a digital puppetry application on a touchscreen, whilst apparently aimless and chaotic, indeed produces shared narratives, that are also presented as instances of agency.

Although not focused on educational activities, Ruckenstein's research in Finland (2013) demonstrates how digital technologies are used by children to create 
social relations, for instance in the care of a virtual pet. While Ruckenstein warns about the potential infiltrations of corporate interests in the lives of children through commercial software, the main point of her work is the observation of children's agency in making creative decisions in the use of digital technologies that transpire in their nondigitally mediated relations. Reinforcing this argument on children's competences and ability to cooperatively build their own cultural words, older researches from Brooker (2008) and Petriwskyj and colleagues (2005) demonstrated that transition is a process of 'mutual adaptation' of children moving between environments, and interacting as they make sense of transitions. However, in this article, a more dynamic and agentic concept of transition is suggested: rather than adapting, children co-construct social spaces where their agency is displayed by claiming and enacting authorship of knowledge. In a circular relationship, hybrid-transition is the context and the outcome of children's agency. This latter claim aligns with Wohlend's research (2015) with children using iPads to produce films with dolls, action figures, and other media toys. Children's play moves between onscreen and offscreen action, as children mix their digital avatars and actual toy figurines, burst into song, recite remembered snippets of dialogue, or imitate characters' voices. Wohlend argues, and the authors of this article would agree with her position, that digital technology enables more cohesive and collaborative moments of storytelling.

Finally, the discussion of the observations undertaken may invite to consider what the practitioner 'did not see', and the impact that her non-acceptance of child D's agency could have on the child's position in the educational relationship, in particular in terms of engagement and personal trust, wellbeing and behaviour. It is here argued for the importance for adults to reflect on self, role and impact regarding the ability to cope with change, as suggested by Dewey (1966), Oatley (1990) and Schon (1987). This is 
particularly important in the context of American Early Years Education, where settings are generally observed as extensions of family and structured around affective care, rather than cognitive development (Lara-Cinisomo et al., 2009) and where emphasis is placed on the development of 'quasi-parental' relationships between adults and children that can be jeopardised by lack of trust.

\section{Conclusion}

The interactions in the Boston pre-kindergarten discussed in this article capture how hybrid-transitions between digital and non-digital realms occur continuously, inviting the reader to reflect on how hybrid-transitions represent an important social space for the expression of children's agency, and a precious opportunity for practitioners to observe how children manage their own learning, environments, curiosity and behaviour.

The observations discussed in the previous sections invite to consider hybrid transitions as a space of change for and from children. Knowledge is generated in the combination of digital experiences and non-digital experiences that are acted and authored by children chiefly through the co-construction of narratives. The use of digital technologies by a small group of young children can be a context for hybridtransitions that open opportunities to negotiate personal memories and narratives, possibly leading to the interactive co-construction of small cultures (Holliday, 2011) that characterise group identities. This article therefore concludes that adults should be mindful of unforeseen but nevertheless important spaces of children's agency in the transition between digital world and non-digital world. Hybrid-transitions inevitably occur between digital explorations and non-digital explorations, and it is here suggested that the observation of interactions during hybrid-transitions and the appreciated of children's epistemic agency can promote a culture of mutual trust and positive 
engagement in educational contexts where the use of digital resources necessarily impact on children's (and adults') experiences and learning.

Although it is believed that this article offers new insights into children's use of digital technologies and its embedment in social interactions, the authors recognise that it is still knowledge produced by adults who observe children'. It is here recognised an epistemological limitation of the study, a limitation that reveals and promotes the need to find ways to fully bring children's voices into research. A methodological limitation concerns the relatively small scale of the study. This was due to reasons of feasibility such as the size and scope of the project, as well as imposed time limits. The authors therefore acknowledge that the findings from this study cannot be easily generalised. Social situations are never sufficiently similar, across space and time, to make a complete replication possible; nevertheless, the authors invite further research interested in the observation of spaces of children's agency in contexts where digital technologies are utilised to support learning.

\section{References}

Bae, B. 2012. Children and teachers as partners in communication: Focus on spacious and narrow interactional patterns. International Journal of Early Childhood, 44(1): 5369.

Baraldi, C. 2014. "Children's participation in communication systems: A theoretical perspective to shape research". Soul of Society: A Focus on the Lives of Children and Youth 18 (18): 63-92

Baraldi, C. 2015. "Promotion of Migrant Children's Epistemic Status and Authority in Early School Life". International Journal of Early Childhood 47 (1): 5-25 
Barnett, W.S., Friedman-Krauss, A.H., Weisenfeld, G.G., Horowitz, M., Kasmin, R., and J.H. Squires. 2017. The State of Preschool 2016: State Preschool Yearbook, New Bath, C. 2013. Conceptualising listening to young children as an ethic of care in early childhood education and care. Children and Society, 27: 361-371.

Brunswick, NJ: National Institute for Early Education Research.

Bjerke, H. 2011. "It's the way to do it. Expressions of agency in child-adult relations at home and school". Children \& Society 25 (2): 93-103.

Bolton, G. 2010. Reflective Practice: Writing and Professional Development. London: Sage

Boston Early Education Department. 2016. Preschool Expansion and Partnership Initiative. Accessed: 12/06/2018

http://www.mass.gov/edu/birth-grade-12/early-education-and-care/provider-andprogram-administration/preschool-expansion-and-partnership-initiative.html Brooker, L. 2008. Supporting Transitions in the Early Years. London: Open University Press

Brown, J., Winsor, D. L., and S. Blake. 2013. Technology and Social-Emotional Development in Early Childhood Environments. Hershey: Information Science Reference.

Buckingham, D. 2002. Small Screens: television for children. London: Leicester University Press

Dahlberg, G., and Moss, P. 2005. Ethics and politics in early childhood education. London: Routledge.

Danby, S., Davidson, C., Ekberg, S. Breathnach, H and K. Thorpe (2016). 'Let's see if you can see me': making connections with Google Earth ${ }^{\mathrm{TM}}$ in a preschool classroom. Children's Geographies, 14 (2): 141-157 
Danby, S., Evaldsson, A., Melander, H. and P. Aarsand (2018). Situated collaboration and problem solving in young children's digital gameplay. British Journal of Educational Technology, 49(5): 959-972

Dewey, J. 1966. Selected Educational Writing. London: Heinemann

Dunn, J. 1988. The Beginnings of Social Understanding. Oxford: Basil Blackwell

Dunn, J., and R. Ploumin. 1990. Separate Lives: why siblings are so different, London: Basic Books

Edwards, S. 2013. By-passing the debate beyond the 'technology question' in the early years. London: Tactyc

Edwards, S. 2013b. Digital play in the early years: A contextual response to the problem of integrating digital technologies and play-based learning in the early childhood curriculum. London: Tactyc

Edwards, S. 2014. "Towards Contemporary Play: Sociocultural theory and the digitalconsumerist context”. Journal of Early Childhood Research 12 (3): 219-233. Author. 2018.

Freeman, C., van Heezik, Y., Stein, A. and K. Hand (2016). Technological inroads into understanding city children's natural life-worlds. Children's Geographies, 14 (2): 158174

Goleman, D. 1996. Emotional Intelligence. London: Bloomsbury

Helsper, E., and R. Enyon. 2010. Digital Natives: where is the evidence? British Educational Research Journal 36(3): 503-520

Hepburn, A., and Bolden, G.B. 2013. Transcription. In Sidnell, J. \& Stivers, T. (Eds). Blackwell Handbook of Conversation Analysis. Oxford: Blackwell, 57-76.

Heritage, J. 2012. Epistemics in action: Action formation and territories of knowledge. Research on Language and Social Interaction, 45(1): 1-29. 
Heritage, J., \& Raymond, G. 2005. The terms of agreement: Indexing epistemic authority and subordination in talk-in-interaction. Social Psychology Quarterly, 68(1): $15-38$

Holliday, A. 2011. Intercultural communication and ideology. London: Sage Iervese, V. and C. Baraldi. Forth. "Frames of narratives: family photography as medium of children's memories".

James, A. 2009. “Agency.”, in The Palgrave handbook of Childhood

Studies, edited by Qvortrup, J, Valentine, G, Corsaro, W., and Honig, M.S.

Basingstoke: Palgrave.

James, A., James, A. 2008. Key concepts in Childhood Studies. London: Sage.

James, A., Jenks, C., and A. Prout. 1998. Theorizing childhood. Oxford: Polity Press. Lansdown, G. 2004. Participation and young children. Early Childhood Matters, 103, $4-14$.

Johansson, I. 2007. "Horizontal Transitions: What Can it Mean for Children in the Early School Years". In Dunlop, A. W. and Fabian, H. (Eds.) Informing Transitions in the Early Years: Research, Policy and Practice. Berkshire: Open University Press, 33-44. Lam, M.S., and Pollard, A. 2006. A Conceptual Framework for Understanding Children as Agents in the Transition from Home to Kindergarten. Early Years, 26 (2): 123-141. Lansdown, G. 2005. Can you hear me? The right of young children to participate in decisions effecting them. Working Paper 36. The Hague: Bernard Van Leer Foundation. Lara-Cinisomo, S., Fuligni, A.S., Daugherty, L., Howes, C., and L.Karoly. 2009. “A Qualitative Study of Early Childhood Educators’ Beliefs about Key Preschool Classroom Experiences”. RAND Working Paper No. WR- 656, Leonard, M. 2016. Sociology of Children, Childhood and Generation. London: Sage. 
Levin, D. 2013. Beyond Remote-Controlled Childhood: Teaching Children in the Media Age. Boston: NAEYC

Levin-Gelman, D. 2014. Design for Kids: Digital Products for Playing and Learning, New York: Rosenfeld Media

Markstroem, A.M., \& Halldén, G. (2009). Children's strategies for agency in preschool. Children and Society, 23, 112-122.

Marsh, J. 2010. "Young children's play in online virtual worlds". Journal of Early Childhood Research 8 (1): 23-41

Marsh, J. and J.Bishop. 2014. Changing Play: Play, Media and Commercial Culture from the 1950s to the present day. Buckingham: Open University Press

Mongeau, L. 2016. What Boston's Preschools Get Right. The Hechinger Report, 02.08.2016. Accessed: 29.05.2018

Available at: http://theatlantic.com/education/archive/2016/08/what-bostons-preschoolsget-right/493952

Mongeau, L. 2017. Why six states still spend nothing on preschool. The Hechinger Report, 16.3.2017, Accessed: 05.04.2018

Available at: http://hechingerreport.org/why-six-states-still-spend-nothing-on-preschool Moosa-Mitha, M. 2005. A difference-centred alternative to theorization of children's citizenship rights. Citizenship Studies, 9: 369-388.

Morgan, A., and J. Siraj-Blatchford. 2013. Using ICT in the Early Years: Parents and Practitioners in Partnership. London: Practical Pre-School Books Mosley, T. 2016. Why Boston Doesn't Have Universal Preschool Yet. The Hechinger Report, 18/08/2016. Accessed 20.02.2018. http://www.wbur.org/edify/2016/08/18/boston-universal-pre-k 
Moss, P. 2009. There are alternatives! Markets and democratic experimentalism in early childhood education and care. The Hague: Bernard Van Leer Foundation Moss, P. 2014. Transformative change and real utopias in early childhood education. A story of democracy, experimentation and potentiality. London: Routledge

Pascal, C., \& Bertram, T. 2009. Listening to young citizens: The struggle to make real a participatory paradigm in research with young children. European Early Childhood Education Research Journal, 17 (2): 249-262.

Petriwskyj, A., Thorpe, K., and Tayler, C. 2005. "Trends in construction of transition to school in three western regions". International Journal of Early Years Education 13 (1): $55-69$

Plowman, L. 2016. Rethinking context: Digital technologies and children's everyday lives. Children's Geographies, 14 (2): 190-202

Plowman, L., Stephen, C., and J. McPake. 2008. "Just picking it up? Young children learning with technology in the home". Cambridge Journal of Education 38 (3): 303319

Plowman, L., Stephen, C. and J.McPake. 2009. Growing up with technology: Young Children Learning in a Digital world. London: Routledge.

Prensky, M. 2001. "Digital Natives, digital immigrants". On the Horizon 9 (5): 1-6 Norrick, N. 2007. “Conversational storytelling”. Chap. 9 in The Cambridge Companion to Narrative, edited by D. Herman, 127-141. Cambridge: Cambridge University Press, Norrick, N. 2012. "Remembering for narration and autobiographical memory2. Language and Dialogue 2 (2): 193-214.

Norrick, N. 2013. “Narratives of vicarious experience in conversation”. Language in Society, 42: 385-406. 
Oatley, K. 1990. Role Transitions in Organizational Life: An Identity-Based

Perspective. Maidenhead: Routledge

Oswell, D. 2013. The Agency of Children. From Family to Global Human Rights.

Cambridge: Cambridge University Press

Radesky, J.S., Schumacher, J., and B. Zuckerman. 2015. "Mobile and Interactive

Media Use by Young Children: The Good, the Bad, and the Unknown”. Paediatrics 135 (1): $1-3$

Ruckenstein, M. 2013. Spatial extensions of childhood: from toy worlds to online communities. Children's Geographies, 11 (4): 476-489

Schön, D. A. 1987. Educating the Reflective Practitioner: towards a new design for teaching and learning in the professions. San Francisco: Jossey-Bass

Author .2016.

Siraj-Blatchford, I. 2006. A curriculum development guide to ICT in Early Childhood Education. Nottingham: Trentham Books

Steven, C. and L Plowman. 2014. "Digital Play.” In Play and Learning in Early

Childhood, edited by L. Brooker, M. Blaise and S. Edwards. London : Sage.

Stone, C. B. and L. Bietti 2016. Contextualizing Human Memory. An interdisciplinary approach to understanding how individuals and groups remember the past. New York: Routledge.

Sutton-Smith, B. 2001. The Ambiguity of Play. Cambridge: Harvard University Press Valentine, K. 2011. Accounting for agency. Children \& Society, 25: 347-358.

Wohlwend, K. E. 2015. One screen, many fingers: Young children's collaborative literacy play with digital puppetry apps and touchscreen technologies. Theory into Practice, 54: 154-162 
Wohlwend, K. E. 2016. USA: Play literacies with toys, popular media, and iPad puppets. The Reading Teacher, 70 (1): 121-129

Wyness, M. 2013. Children's participation and intergenerational dialogue: Bringing adults back into the analysis. Childhood, 20 (4): 429-442.

Wyness, M. 2014. Childhood. London: Polity. 